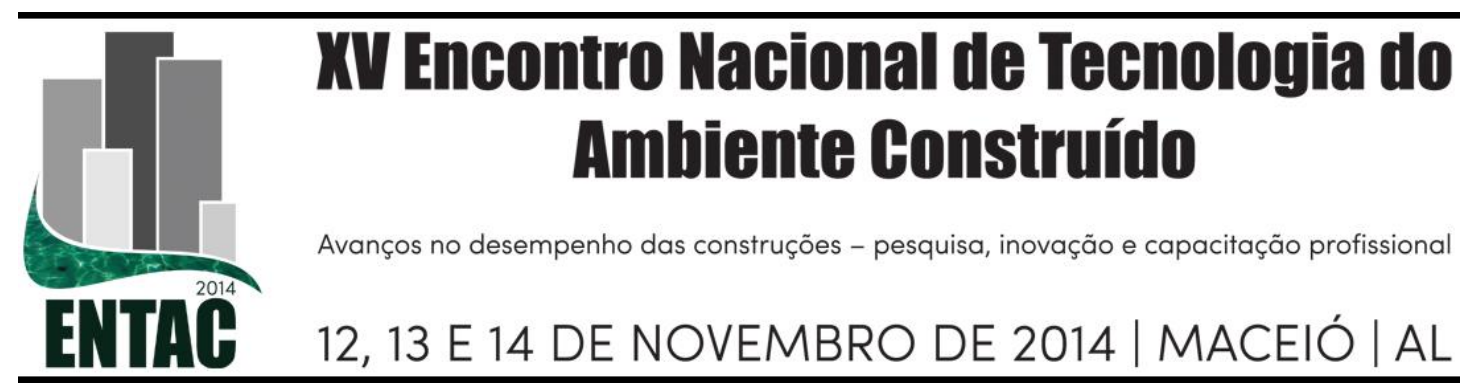

\title{
AVALIAÇÃO DE BLOCOS DE CONCRETO PRODUZIDOS COM PET RECICLADO
}

\author{
CÂNDIDO, Luis Felipe (1); BARRETO, José Maurício Lima (2); CABRAL, \\ Antônio Eduardo Bezerra (3)
}

(1) PEC/UFC, e-mail: luisf_civil@yahoo.com.br, (2) PEC/UFC, e-mail: mauriciobarreto@ufc.br, (3) GPMAT/UFC, e-mail: eduardo.cabral@ufc.br

\begin{abstract}
RESUMO
Tento em vista materiais potencialmente recicláveis no contexto urbano, o PET (polietileno tereftalato) já vem sendo utilizado em diversos segmentos industriais, porém este material, ainda é pouco utilizado na construção civil. Um estudo realizado pela Associação Brasileira da Indústria do PET (ABIPET) em 2011 revelou que houve um acréscimo de 304\% na recuperação do PET de 1994 a 2011, totalizando cerca 294 Ktons cujo principal destino final foi aplicações nas indústrias têxteis $(39,30 \%)$, não sendo contabilizada parcela de consumo para construção civil. Assim, o presente trabalho apresenta os resultados de uma pesquisa experimental desenvolvida com o intuito de testar o uso do PET triturado em substituição da areia natural nas frações de 15\%, 30\% e 45\% para a fabricação de blocos de concreto prensado com incorporação de PET reciclado. Foram determinados às características geométricas, os índices físicos e características mecânicas, tais como massa seca, absorção de água, condutividade térmica e resistência à compressão. Ao serem analisados os resultados, pode-se concluir que o teor que apresentou os melhores resultados foi de $15 \%$ de PET, devido ao acréscimo de sua resistência à compressão em relação aos demais teores, destacando-se ainda uma menor absorção, resultante de seu maior empacotamento e melhor homogeneidade do compósito.
\end{abstract}

Palavras-chave: Bloco de Vedação, Sustentabilidade, PET

\begin{abstract}
Among the materials with potential of recycle, the PET (polyethylene terephthalate), is widely used in different industrials sectors. However, the use of this recycled material in construction industry is insignificant. In 2011, a study conducted by Brazilian Association of PET Industry (ABIPET) revealed a growth of the level of recycling of PET in 304\% between 1994 and 2011. In absolute numbers this represents about 294 kilotons. This result represents the second in recycling of PET around the world, just behind of Japan. The main application of PET recycled are performed in textile industry $(39,30 \%)$ and the consumption by construction industry is so small that it was not recorded in survey. Thus, this paper aims to presents the results of an experimental research developed about the use of PET recycled replacing by volume of fine aggregate in fraction of 15\%,30\% and 45\%. The geometric, physical and mechanical characteristics were found, between them, the dry mass, water absorption, thermal conductivity and compressive strength. Can be conclude the content that replacing of $15 \%$ of PET achieved the best results due of the biggest compressive strength, lower of water absorption, resulting from its higher homogeneity and better wrapping of composite with PET recycled.
\end{abstract}

Keywords: Concrete blocks, Sustainability, PET.

\section{INTRODUÇÃO}

A cadeia produtiva da construção civil é responsável pela transformação do ambiente natural em ambiente construído que precisa ser permanentemente atualizado e mantido. Dada a complexidade e extensão de seu impacto no meio ambiente, na economia e na 
sociedade, a construção de políticas, o desenvolvimento e aplicação de novos conhecimentos (inovação) de forma sistêmica são de suma importância à manutenção do equilíbrio do planeta que vem sendo alterado significativamente pelo desenvolvimento promovido pela humanidade (AGOPYAN; JOHN, 2011).

Nesse contexto, o conceito de sustentabilidade como a busca de um equilíbrio entre proteção ambiental, justiça social e viabilidade econômica é um tema bastante discutido, dada demanda crescente de novas moradias e os novos padrões e requisitos de qualidade impostas pela sociedade (AGOPYAN; JOHN, 2011).

Tendo em vista os materiais potencialmente recicláveis no contexto urbano, o reciclado do PET (polietileno tereftalato) já vem sendo utilizado em diversos segmentos industriais, sendo ainda pouco utilizado na construção civil, como revela um censo realizado pela Associação Brasileira da Indústria do PET (ABIPET) em 2011. Esta pesquisa apresenta um acréscimo de 304\% na recuperação do PET de 1994 a 2011, totalizando cerca 294 ktons cujo principal destino final é a indústria têxtil (39,30\%), não sendo contabilizada parcela de consumo para construção civil (ABIPET, 2011).

Revisitando a literatura na busca de uma utilização viável do PET reciclado, dentro da temática de desenvolvimento de produtos alternativos, uma pesquisa realizada na argentina pelo CEVE (Centro Experimental de la Vivienda Económica) apresentou a aplicação do reciclado do PET na fabricação de blocos sem função estrutural em substituição total do agregado miúdo. Os resultados foram satisfatórios e revelaram que algumas propriedades significativas como resistência à compressão, absorção, condutibilidade térmica melhoraram em relação a outros tipos de bloco com a mesma função (BERETTA, 2008).

Partindo da experiência do CEVE e na busca de materiais alternativos que contribuíssem com a sustentabilidade, o presente trabalho tem por objetivo produzir e avaliar blocos de vedação vertical em concreto sem função estrutural com substituição do agregado miúdo por PET reciclado.

Para tal, buscou-se sistematizar o arcabouço teórico que constituiu o presente trabalho, partindo-se do tema sustentabilidade e construção civil, especificamente materiais alternativos e tecnologias apropriadas, chegando-se ao PET e, por fim, o desenvolvimento e produção do bloco em apreço neste estudo.

\section{REFERENCIAL TEÓRICO}

\subsection{Sustentabilidade e construção civil}

A sustentabilidade é entendida como um tripé que integra as perspectivas ambiental, social e econômica. Ainda mais, a sustentabilidade de uma empresa, deve ser entendida nestas três perspectivas como proteção ambiental, crescimento econômico e justiça social (ELKINGTON, 1999).

O setor da construção civil é um dos principais agentes de degradação ambiental, dada sua extensa e complexa cadeia produtiva que impacta no consumo de recursos naturais e na emissão de agentes poluentes no meio ambiente (AGOPYAN; JOHN, 2011).

Devido a este fato, existe uma crescente demanda dos clientes por produtos sustentáveis que obrigam as empresas a darem cada vez mais atenção para essa temática (PARDINI, 
2009). Uma alternativa que contribui para essa problemática está no desenvolvimento de novos produtos e componentes alternativos à construção.

A busca de soluções inovadoras e sustentáveis para construção civil deve estar associada ao conceito de tecnologia apropriada que contempla os conceitos de sustentabilidade. A tecnologia apropriada está atrelada a um determinado modelo de desenvolvimento e cultura de uma sociedade e exige uma integração das esferas técnicas, sociais, políticas, econômicas, éticas e ambientais (AGOPYAN; JOHN, 2011).

\subsection{Pet e Reciclagem}

O PET é um poliéster, polímero termoplástico produzido através da polimerização que proporciona a união de monômeros para formar polímeros (ABIQUIM 2004 apud VALT, 2009). Um uso bastante comum deste material é na fabricação de garrafas plásticas, largamente utilizadas na indústria de bebidas.

Preocupado com a geração de passivos ambientais, a ABIPET realiza desde 1994 um censo sobre o nível de reciclagem no Brasil. Em sua última edição, o senso revelou que em 2011 57,10\% do PET produzido foi reciclado. A pesquisa indica que houve um acréscimo de 304\% na porcentagem de reciclado, saindo de cerca de 15 ktons em 1994 para 294 ktons em 2011. Além disso, pode-se afirmar que a produção anual de PET no brasil chegou a aproximadamente 515 ktons em 2011. Considerando-se que uma garrafa PET de $2 \mathrm{~L}$ pesa $57 \mathrm{~g}$ a conta equivale a cerca de 9 bilhões de unidades desse tipo de embalagem (ABIPET, 2011).

O sucesso deste material como reciclado deve-se à sua excelente relação entre as propriedades mecânicas, térmicas e o custo de produção (MACDONALD, 2002 apud ROMÃO, 2009).

Em 2011, Valt realizou um estudo sobre o ciclo de vida das embalagens de PET com vários teores de reciclagem. $\mathrm{O}$ estudo apresenta dados para fabricação de uma garrafa PET para refrigerantes, incluindo sua reciclagem resultando em um consumo significativo de recursos naturais para o processo em análise (VALT, 2004).

Cruzando-se os passivos gerados da reciclagem de embalagens de PET levantados por Valt com a produção anual levantada pela ABIPET, o consumo de recursos naturais é de aproximadamente de $1,5 \times 10^{10} \mathrm{~J}, 4230$ megatoneladas de água bruta e são gerados 472 megatoneladas de resíduos totais

Estes dados justificam a escolha do material PET como material a ser reciclado, pois além das boas propriedades citadas por MacDonald, à reciclagem, em geral, precisar de processos químicos que também geram passivos ao meio ambiente. Desta forma, o presente trabalho apresenta uma alternativa que não demanda de processos químicos para reciclar este material.

\subsection{Compósitos cimentícios com incorporação e PET reciclado}

Para Betioli et al. (2004), materiais constituídos de matriz cimentícia, como concreto e argamassa, são frágeis e com baixa resistência à tração, baixa ductilidade e baixa energia de absorção (tenacidade). Uma das principais características de matrizes de cimento Portland é a alta alcalinidade da mistura com $\mathrm{pH}$ superior a 13. Outro fator marcante é o alto calor de hidratação do cimento na reação para formação da pasta. 
Para De Paoli (2008, apud Romão, 2009), a degradação do PET pode ser iniciada por cisalhamento, calor, oxigênio, resíduos de catalisador, dentre outros, conduzindo à degradação mecânica, térmica, química ou ainda a uma combinação destas. Têm-se, nesse sentido, fatores suficientes para acreditar que uma degradação acelerada dos compósitos com adição de PET pode ocorrer, como ocorre com as fibras vegetais devido aos processos de preparação deste material para incorporação em compósitos cimentícios (como é o caso da trituração).

Quanto a durabilidade, Betioli et al. (2004) realizou um estudo sobre a degradação do PET em compósitos cimentícios cujos resultados indicaram uma interação da cadeia polimérica da fibra de PET com o meio agressivo com o aparecimento de grupos $\mathrm{SO}_{4}^{2-}$. "As fibras foram atacadas pelas soluções de ácido sulfúrico $\left(\mathrm{H}_{2} \mathrm{SO}_{4}\right.$ a $0,1 \mathrm{M} ; 1 \mathrm{M}$ e $10 \mathrm{M})$, indicando a existência de degradação de fibras de PET nessas matrizes devido à hidrólise alcalina quando imersas na matriz de cimento" (BETIOLI, 2004).

\section{MATERIAIS E MÉTODOS}

\subsection{Caracterização dos materiais}

O cimento utilizado foi do tipo Portland - CP II Z - 32 do fabricante Poty com massa específica de $3,10 \mathrm{~g} / \mathrm{cm}^{3}$ e massa unitária de $1,42 \mathrm{~g} / \mathrm{cm}^{3}$. Utilizou-se o pó de pedra britada de mineralogia granítica adquirida na Pedreira Cebrita, cujos resultados da caracterização são apresentados na Tabela 1.

Tabela 1 - Índices físicos do agregado miúdo: pó de pedra

\begin{tabular}{lcc}
\hline \multicolumn{1}{c}{ Índice } & Referências Normativas & Resultados \\
\hline Dimensão máxima característica $(\mathrm{mm})$ & ABNT NM 248:2003 & 4,75 \\
\hline Módulo de finura & ABNT NM 248:2003 & 2,59 \\
\hline Massa unitária solta $\left(\mathrm{g} / \mathrm{cm}^{3}\right)$ & ABNT NBR NM 45:2006 & 1,59 \\
\hline Massa unitária compactada $\left(\mathrm{g} / \mathrm{cm}^{3}\right)$ & ABNT NBR NM 45:2006 & 1,73 \\
\hline Massa específica $\left(\mathrm{g} / \mathrm{cm}^{3}\right)$ & ABNT NBR NM 52:2009 & 2,54 \\
\hline Material Fino $(\%)$ & ABNT NBR NM 46:2003 & 14,72 \\
\hline
\end{tabular}

Fonte: dos autores.

Utilizou-se o PET reciclado e triturado oriundo de uma recicladora da Região Metropolitana de Fortaleza, cujas características determinadas foram apresentadas na Tabela 2.

Tabela 2 - Índices físicos do agregado miúdo: pó de pedra

\begin{tabular}{lcc}
\hline \multicolumn{1}{c}{ Índice } & Referências Normativas & Resultados \\
\hline Dimensão máxima característica $(\mathrm{mm})$ & ABNT NM 248:2003 & 4,75 \\
\hline Módulo de finura & ABNT NM 248:2003 & 5,38 \\
\hline Massa unitária solta $\left(\mathrm{g} / \mathrm{cm}^{3}\right)$ & ABNT NBR NM 45:2006 & 0,26 \\
\hline Massa específica $\left(\mathrm{g} / \mathrm{cm}^{3}\right)$ & ABNT NBR NM 52:2009 & 1,37 \\
\hline
\end{tabular}

Fonte: dos autores. 


\subsection{Dosagem do concreto e confecção dos blocos}

Para o estudo, foram analisados quatro traços de argamassa "farofada" sendo três contendo o PET triturado em substituição ao volume do pó de pedra nos teores $15 \%$, $30 \%$ e $45 \%$. Para o traço de referencia (sem PET) tomou-se um traço usual de uma empresa de pré-moldados da região, 1:5:1 (cimento, pó de pedra e água). Para a execução das misturas, foi utilizada uma argamassadeira de giro horizontal com capacidade de 173 litros.

Realizou-se a confecção de blocos testes (ou blocos pilotos) para avaliar as possíveis falhas e dificuldades para execução do experimento e verificou-se que a manutenção de fator água/cimento fazia com que a mistura perdesse consistência à medida que fossem realizadas as substituições planejadas. Desta forma, optou-se pela adição de água na composição com avaliação expedita da consistência da argamassa através do teste manual da umidade ótima apresentado por Agopyan e John (2011).

Paras moldagens dos blocos foi utilizada uma prensa manual conforme a Figura 4-a. A compactação da mistura foi realizada manualmente por um único operador tentando minimizar efeitos de variação da energia de compactação utilizada. Foram confeccionados 12 blocos para cada tipo de traço totalizando 48 blocos fabricados (Figura 4-b).

Figura 1 - Moldagem dos blocos com prensa manual

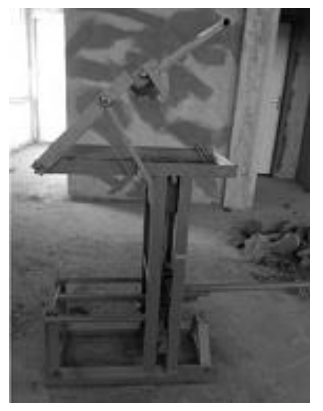

a) Prensa utilizada

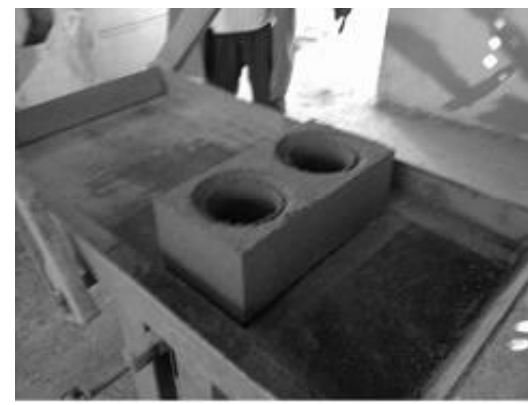

b) extrusão do bloco

Fonte: dos autores.

Após a moldagem foram tomados os devidos cuidados no transporte e manuseio dos blocos recém-fabricados. Estes foram colocados em um ambiente protegido e realizado a cura com aspersão de água durante os sete primeiros dias. Passados vinte e oito dias, iniciaram-se os ensaios de características geométricas, físicas e mecânicas dos blocos confeccionados.

\subsection{Ensaios de caracterização dos blocos}

Inicialmente, foram numeradas e identificadas as amostras dos blocos separadas por diferentes teores de PET para serem utilizadas nos ensaios de caracterização geométrica, determinação de índices físicos e mecânica, além dos ensaios especiais.

\subsubsection{Características geométricas e físicas}

Foram determinadas as dimensões efetivas, a área bruta e a área líquida dos blocos com uma amostra de 10 unidades para cada teor de substituição. Os métodos para 
determinação das dimensões do bloco vazado de concreto simples sem função estrutural são descritos na ABNT NBR 12118:2013 bem como a determinação da área bruta.

Após a execução dos procedimentos para determinar as características geométricas, os dez blocos foram colocados na estufa a uma temperatura de $105^{\circ} \mathrm{C}$, por vinte e quatro horas e conforme as prescrições da ABNT NBR 12118:2013 determinaram-se a absorção de água e a massa seca.

\subsubsection{Condutibilidade térmica}

$\mathrm{Na}$ intenção de determinar uma característica de conforto ambiental foi montado um experimento para determinação da condutibilidade térmica. Esse índice indica a quantidade de calor transmitida através de uma espessura (L), numa direção normal a superfície de área $(\mathrm{A})$, devido ao gradiente de temperatura $(\Delta \mathrm{T})$, sob condições de estado fixo e quando a transferência de calor dependente apenas do gradiente de temperatura sendo calculado pela (1.

$$
\frac{\mathrm{Q}}{\Delta \mathrm{T}}=\frac{\mathrm{K} x \mathrm{~A}}{\mathrm{~L}}
$$

Onde: $\quad \mathrm{Q} / \Delta \mathrm{T}-$ Energia transferida $(\mathrm{J} / \mathrm{s})$.

$\Delta \mathrm{T}-$ Diferencia de temperatura $(\mathrm{K})$

K- Condutibilidade térmica (W/m.K). L-Espessura (m)

$$
\text { A - Área }\left(\mathrm{m}^{2}\right)
$$

Para a realização do ensaio de condutividade térmica foi confeccionada uma amostra de cada teor, constituída com quatro blocos justa postos, conforme a Figura 2.

\section{Figura 2 - Ensaio de condutividade térmica}

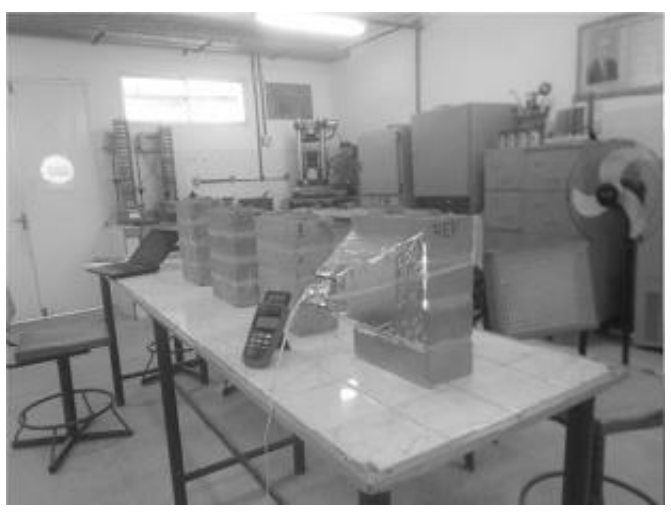

a) esquema do ensaio

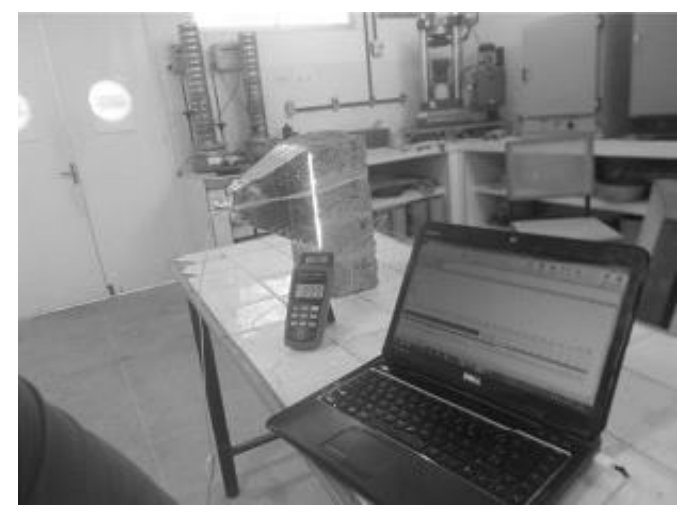

b) medição dos resultados

Fonte: dos autores.

Os equipamentos utilizados para realização foram uma fonte emissora de calor, tipo refletor, com uma lâmpada incandescente de 150 w. Para a medição das temperaturas foram utilizados um Termômetro Digital da marca Mimipa, modelo MT 455, com dois termopares, responsáveis pela leitura de temperatura das duas faces da parede ensaiada.

O tempo de duração de cada ensaio foi de três horas ininterruptas, com a realização das medições de temperaturas a cada 5 minutos, em ambiente com temperatura controlada, possibilitando a observação das temperaturas internas e externas e a estabilização do fluxo de calor para o cálculo da condutividade térmica. 


\subsubsection{Características mecânicas}

Para a resistência à compressão do bloco foi utilizado à norma ABNT NBR 12118: 2013. Ao final dos vinte e oito dias da moldagem, os cinco blocos de cada teor, com as características geométricas e físicas determinadas, foram capeados (com espessura inferior a $5 \mathrm{~mm}$ ) com argamassa de regularização.

Após a regularização aplicada nas duas faces dos componentes, decorridas vinte e quatro horas, os blocos foram imersos em água por vinte e quatro horas antes do rompimento. Os corpos de prova foram rompidos na máquina universal de ensaio da marca EMIC, modelo DL100T.

\subsection{Viabilidade econômica}

Durante a confecção dos blocos verificou-se que é possível confeccionar 192 blocos prensados por dia com um único operário. Realizou-se a cotação dos insumos de cimento ( $\mathrm{R} \$ 20,00 /$ saco de $50 \mathrm{~kg}$ ), pó de pedra $\left(\mathrm{R} \$ 26,00 / \mathrm{m}^{3}\right)$ e PET $(\mathrm{R} \$ 2,80 / \mathrm{kg})$. O valor da mão de obra foi calculado a partir do dissídio da construção civil à época ( $\mathrm{R} \$ 3,17 / \mathrm{h}$ para um servente) e aplicou-se uma taxa de $125 \%$ de leis sociais. Os custos com investimento iniciais foram desconsiderados para esta análise.

\section{ANÁLISE E DISCUSSÃO DOS RESULTADOS}

Em síntese, os resultados obtidos são apresentados na Tabela 3.

Tabela 3 - Resumo das características físicas e mecânicas ensaiadas

\begin{tabular}{|c|c|c|c|c|}
\hline \multirow[b]{2}{*}{ AMOSTRA } & \multicolumn{3}{|c|}{ Características Físicas } & \multirow[b]{2}{*}{$\begin{array}{l}\text { Resist. } \\
\text { Com. } \\
\text { (Mpa) }\end{array}$} \\
\hline & $\begin{array}{l}\text { Massa } \\
\text { Seca } \\
(\mathrm{kg})\end{array}$ & $\begin{array}{c}\text { Absorção } \\
(\%)\end{array}$ & $\begin{array}{c}\text { Condutividade } \\
\text { térmica } \\
(\mathbf{W} / \mathbf{m} . \mathbf{K})\end{array}$ & \\
\hline REFERÊNCIA & 2,88 & 12,77 & 2,33 & 5,58 \\
\hline $15 \%$ & 2,84 & 10,92 & 2,28 & 5,71 \\
\hline $30 \%$ & 2,58 & 13,34 & 2,36 & 3,54 \\
\hline $45 \%$ & 2,56 & 17,19 & 2,05 & 2,73 \\
\hline
\end{tabular}

Fonte: dos autores.

As características geométricas dos blocos são apresentadas na Tabela 4.

Tabela 4 - Características geométricas dos blocos

\begin{tabular}{|c|c|c|c|c|c|c|c|c|}
\hline \multirow{2}{*}{ Amostra } & \multicolumn{3}{|c|}{ Dimensões efetivas } & \multicolumn{3}{|c|}{$\begin{array}{l}\text { Variação em relação ao } \\
\text { bloco de referência }(\%)\end{array}$} & \multicolumn{2}{|c|}{ Área $\left(\mathrm{cm}^{2}\right)$} \\
\hline & $\mathbf{L}(\mathbf{c m})$ & $\mathrm{C}(\mathrm{cm})$ & $\mathbf{H}(\mathbf{c m})$ & $\Delta \mathbf{L}$ & $\Delta \mathrm{C}$ & $\Delta \mathbf{H}$ & Bruta & Líquida \\
\hline REFERÊNCIA & 12,5 & 25 & 6,96 & - & - & - & 312,5 & 208,44 \\
\hline $15 \%$ & 12,57 & 25,06 & 7,03 & 0,53 & 0,24 & 1,1 & 314,92 & 209,82 \\
\hline $30 \%$ & 12,66 & 25,12 & 7,32 & 1,31 & 0,49 & 5,2 & 318,14 & 214,82 \\
\hline $45 \%$ & 12,74 & 25,35 & 7,72 & 1,92 & 1,39 & 10,9 & 322,92 & 207,62 \\
\hline
\end{tabular}

Fonte: dos autores.

Ao analisar a variação das dimensões para o bloco de referência, foi observada pouca variação de comprimento $\left(\Delta \mathrm{C}_{\text {máx }}=1,39 \%\right)$ e largura $\left(\Delta \mathrm{L}_{\text {máx }}=1,92 \%\right)$, porém, em relação 
à altura observou-se uma variação bastante significativa chegando-se a $\Delta \mathrm{L}_{\text {máx }}=10,9 \%$ em relação ao traço de referencia.

Atribui-se essa variação da altura à capacidade de absorção da energia dada, na moldagem, pelo PET, visto que a pega do cimento ainda está se iniciando. Desta forma, verificou-se que após a dissipação da energia aplicada na prensagem do compósito que contém o PET reciclado existiu uma pequena expansão volumétrica do bloco.

As características físicas do bloco são apresentadas na Tabela 5.

Tabela 5 - Características físicas do bloco

\begin{tabular}{|c|c|c|c|c|c|c|c|c|}
\hline \multirow{3}{*}{ Característica } & \multirow{2}{*}{\multicolumn{2}{|c|}{ REFERÊNCIA }} & \multicolumn{6}{|c|}{$\begin{array}{c}\text { Comportamento em relação ao traço de } \\
\text { referência }\end{array}$} \\
\hline & & & \multicolumn{2}{|c|}{$15 \%$} & \multicolumn{2}{|c|}{$30 \%$} & \multicolumn{2}{|c|}{$45 \%$} \\
\hline & Média & $\mathrm{CV}$ & Média & $\mathrm{CV}$ & Média & $\mathrm{CV}$ & Média & $\mathrm{CV}$ \\
\hline Massa Seca (kg) & 2,88 & $5,41 \%$ & 2,84 & $3,26 \%$ & 2,58 & $5,33 \%$ & 2,56 & $2,40 \%$ \\
\hline Absorção (\%) & 12,77 & $7,78 \%$ & 10,92 & $3,48 \%$ & 13,34 & $5,55 \%$ & 17,19 & $16,92 \%$ \\
\hline $\begin{array}{l}\text { Condutividade térmi } \\
(\mathrm{W} / \mathrm{m} \cdot \mathrm{K})\end{array}$ & 2,33 & $1,70 \%$ & 2,28 & $1,29 \%$ & 2,36 & $0,90 \%$ & 2,05 & $0,94 \%$ \\
\hline
\end{tabular}

Fonte: dos autores.

Para massa seca, observa-se que houve uma diminuição com a colocação do PET chegando a um valor de $11,1 \%$ para amostra de $45 \%$.

Para absorção, entre o traço de referência e o traço de $15 \%$ houve uma redução de $14,49 \%$ indicando que o PET contribuiu positivamente para o compósito nesse teor. Para maiores teores de substituição, a absorção não diminuiu. Infere-se, portanto, que o PET no teor de $15 \%$ contribuiu para diminuição do seu índice de vazios.

A condutividade térmica foi determinada com a média dos valores de $\mathrm{K}$ a partir do estabelecimento de um fluxo constante de calor através do bloco observado no Gráfico 1 a partir de 90 min de ensaio.

\section{Gráfico 1 - Curva de condutividade térmica das paredes ensaiadas}

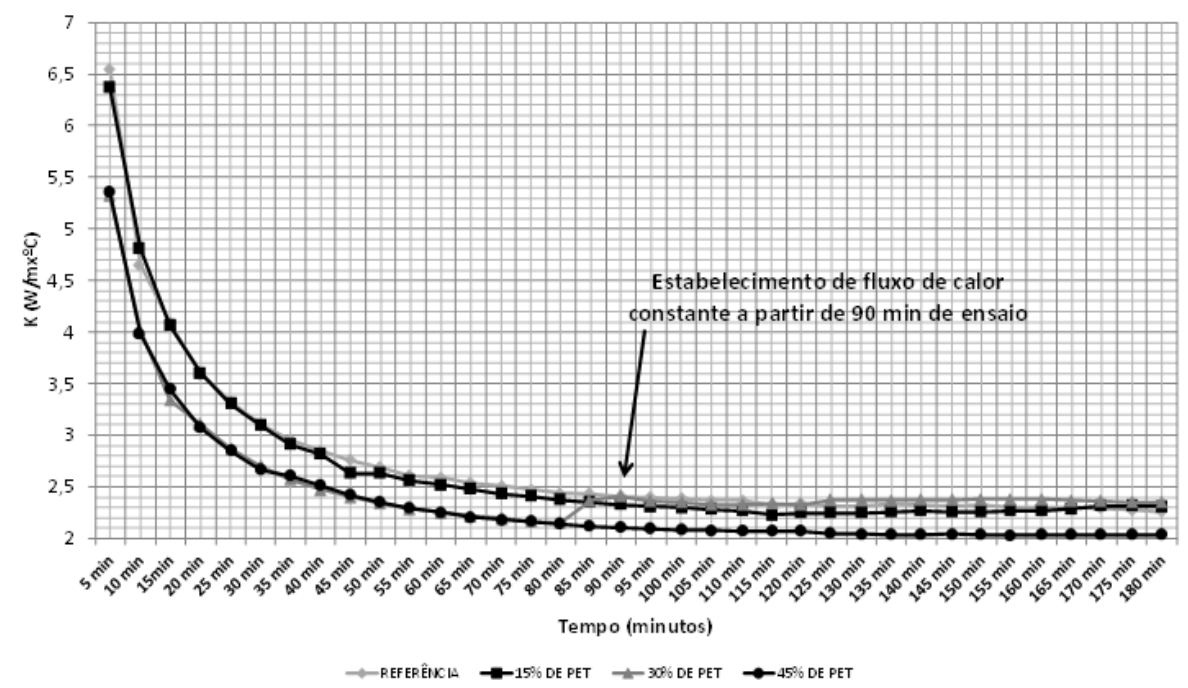

Fonte: dos autores. 
Com relação à condutividade térmica, o valor médio deste índice foi de $2,23 \mathrm{~W} / \mathrm{m} . \mathrm{K}$. Esse valor, se comparado ao do tijolo de concreto que, conforme a ABNT NBR 152202 é de 1,75 , verifica-se um acréscimo de $27,4 \%$ em relação ao valor padronizado. Vale observar que para o experimento o valor foi abaixo do traço de referência em 4,3\%.

Esse fenômeno pode está vinculado à baixa quantidade de ar presente nos vazios do compósito os quais, quando submetidos a um fluxo de calor, entram em processo de transmitância precocemente, corroborando com o resultado de baixa absorção.

A Tabela 6 apresenta as características mecânicas dos blocos produzidos.

Tabela 6 - Resistência à compressão dos blocos

\begin{tabular}{cccc}
\hline \multirow{2}{*}{ Amostra } & \multicolumn{2}{c}{ Resistência $(\mathbf{M P a})$} & $\begin{array}{c}\text { \% em relação à } \\
\text { referência }\end{array}$ \\
\cline { 2 - 4 } & Média & $\mathbf{C V}$ & - \\
\hline REFERÊNCIA & 5,58 & $4,48 \%$ & - \\
\hline $15 \%$ & 5,71 & $6,65 \%$ & $2,33 \%$ \\
\hline $30 \%$ & 3,54 & $11,86 \%$ & $-35.73 \%$ \\
\hline $45 \%$ & 2,73 & $11,36 \%$ & $-80,51 \%$ \\
\hline
\end{tabular}

Fonte: dos autores.

Observa-se que a amostra com 15\% apresentou resistência superior aos demais teores com 2,33\% em relação à amostra de referência corroborando com o indício observado na absorção: redução da absorção para o teor de $15 \%$. Por fim, em relação à viabilidade financeira observou-se que o preço/ unidade produzida variou entre $\mathrm{R} \$ 0,43$ e $\mathrm{R} \$ 0,47$ de acordo com o teor de PET na amostra.

\section{CONSIDERAÇÕES FINAIS}

Ao serem analisados os resultados dos ensaios com os blocos vazados com vários teores de PET em substituição do agregado miúdo, pode-se concluir que o teor que apresentou os melhores resultados foi de $15 \%$ de PET. Houve uma redução na massa seca, absorção e condutividade térmica e um aumento da resistência à compressão do bloco. Esses resultados indicam um maior empacotamento e melhor homogeneidade do compósito para o referido teor.

Ademais, pode-se afirmar que a substituição do agregado miúdo por PET em maiores frações prejudicou o desempenho dos blocos frente aos principais índices analisados.

Por fim, a viabilidade econômica do presente componente mostrou-se bastante competitivo com um custo aproximado de $\mathrm{R} \$ 0,43$ para o teor de que obteve melhores resultados. Este valor está dentro da ordem de grandeza dos tijolos comerciais consultados cujo valor de mercado gira em torno de $\mathrm{R} \$ 0,40$. Porém, o acréscimo de 3 centavos no custo de produção oferece em contrapartida a diminuição de vários passivos decorrentes da destinação incorreta do PET ou até mesmo da reciclagem deste material.

Os resultados indicam, portanto, indícios de viabilidade técnico-econômica para sua produção e utilização em larga escala. No entanto, frente aos indícios de degradação apresentados por Betiolini, experimentos complementares devem ser conduzidos, principalmente sobre a durabilidade destes blocos, carecendo assim, de um segundo estudo mais aprofundado. Assim, amostras do produto foram guardadas para uma futura avaliação de durabilidade em idades mais avançada (1 ano após sua confecção). 


\section{AGRADECIMENTOS}

Os autores agradecem a CAPES e a recicladora São José pelo apoio a pesquisa.

\section{REFERÊNCIAS BIBLIOGRÁFICAS}

ABIPET - Associação Brasileira da Industria do PET. $8^{\circ}$ Censo da reciclagem do PET no Brasil: 2011. Disponível em: <

http://www.abipet.org.br/index.html?method=mostrarInstitucional\&id=7> Acesso em: 17.07.2013.

ABNT - Associação Brasileira de Normas Técnicas NBR NM 248: Agregados - Determinação da composição granulométrica. Rio de Janeiro: 2003.

NBR 15220-2: Desempenho térmico de edificações. Parte 2: Método de cálculo da transmitância térmica, da capacidade térmica, do atraso térmico e do fator solar de elementos e componentes de edificações. Rio de Janeiro: 2005

NBR NM 45: Agregados - Determinação da massa unitária e do volume de vazios. Rio de Janeiro: 2006.

NBR NM 52: Agregado miúdo - Determinação da massa específica e massa específica aparente. Rio de Janeiro: 2009

NBR 12118: Blocos vazados de concreto simples para alvenaria - Métodos de ensaio. Rio de Janeiro: 2013.

AGOPYAN, V; JOHN, V. M. O Desafio da Sustentabilidade na Construção Civil. Ed. Edgard Blucher, v.5, 2011.

BERETTA, H; GATANI, M; GAGGINO, R. ARGÜELO, R. Ladrillos de plástico reciclado: uma propuesta ecológica para la vivenda social. $1^{\text {a }}$ ed. Buenos Aires: Nobuko, 2008.

BETIOLI, A. M; SILVA, D. A; GLEIZE, P. J. P; ROMAN, H. R; GOMEZ, L. A. Degradação de fibras de PET em materiais à base de cimento portland. Anais: X Encontro Nacional de Tecnologia do Ambiente Construído. São Paulo, 2004.

ELKINGTON, J. Cannibals with forks. Canada: New Society, 1999.

PARDINI, A. F. Contribuição ao entendimento da aplicação da certificação LEED e do conceito de custos no ciclo de vida em empreendimentos mais sustentáveis no Brasil.

Dissertação (Mestrado Arquitetura e Urbanismo). Universidade Estadual de Campinas, Campinas, 2009.

ROMÃO, W; SPINACÉ, M. A. C; De PAOLI; M. A. Poli (teleftalato de Etileno) PET: uma revisão sobre os processos de síntese, mecanismos de degradação e sua reciclagem. Polímeros: Ciência e Tecnologia. Vol. 19, ${ }^{\circ}$ 2, p 121-132, 2009. Disponível em: <

http://www.scielo.br/scielo.php/script_sci_serial/pid_0104-1428/lng_pt/nrm_iso > Acesso em: 12.07.2013.

VALT, R. B. G. Análise do ciclo de vida de embalagens PET, de alumínio e de vidro para refrigerantes no Brasil variando a taxa de reciclagem dos materiais. Dissertação (Mestrado em Engenharia de Processos Térmicos e Químicos). Universidade Federal do Paraná. Curitiba, 2004. 209p. 